\title{
Theoretical Model of Special Product Design for the Elderly
}

\author{
Gangqiang Zheng, Teng Dong, Yuwei Deng \\ School of Art and Design, Wuhan University of Technology, Wuhan, China \\ Email: zhenggq@whut.edu.cn
}

Received 22 May 2015; accepted 31 January 2016; published 3 February 2016

Copyright @ 2016 by authors and Scientific Research Publishing Inc.

This work is licensed under the Creative Commons Attribution International License (CC BY). http://creativecommons.org/licenses/by/4.0/

(c) (i) Open Access

\begin{abstract}
As ageing in current society is gradually increasing, it is urgent to study product design for the elderly, exploring the theoretical system of elderly product design is of great significance. In order to guide product design from the perspective of theory, this paper forms a study on the theoretical model of special product design for elderly people. It explains the factors influencing special product design for the elderly. The similarities and differences between special product design for the elderly and barrier free design and universal design are analyzed with the use of the comparative analysis method; concept, nature and characteristics of special product design for the elderly are summarized. Basic principles of special product design for the elderly are summarized from function, form, ergonomics, structure, value and other aspects. The theoretical model of special product design for the elderly which includes "Influence factors analysis-design theory inductiontest \& evaluation" is established, which offers a reference to the development of special product design theory for the elderly.
\end{abstract}

\section{Keywords}

Elderly People, Special Product, Design Principles, Theoretical Model

\section{Introduction}

With the increasing development of social civilization and constant improvements in living conditions and medical levels, average life expectancy increases. This has caused increasing population ageing in modern society (Charness, 2008). Family structure and scale change because of population aging and low birth rate. The elderly account for an increasing proportion of total population, which leads to gradual weakening of family provide for the aged function (Luo, 2014). Life and care problems of the elderly have become increasingly prominent (Bertera et al., 2007). Under this background, the development of special products for the elderly can enhance the 
daily life ability of the elderly and improve their life quality, which is of great importance for promoting social development. However the public's perception on population aging is still very limited and the importance of special products for the elderly has not been widely recognized in the society. Study on the design of special products for seniors is urgently needed as at present, there are many problems in the design of special products for the elderly. For example, there is no systematic and targeted product development (Dou \& Zheng, 2013). In addition, it is difficult to separate this from barrier free design and universal design. A relatively complete theoretical system has not been in place, so it is urgent to explore design concept and rules of special products design for the elderly, identify basic design principles and related factors and gradually build a theory system of special product design for the elderly, in order to guide design practice.

\section{Analysis of Background Factors Affecting Special Product Design for the Elderly}

To explore the theory of special product design for the elderly, it is necessary to combine and comprehensively analyze macro environment characteristics of human society development, market status and the associated specific factors. The analysis of background factors affecting special product design for the elderly can provide support for building special product design theory for the elderly.

\subsection{Macroscopic Factors: Population Aging and Social Development Characteristics}

Development history of human society can be regarded as a coordinate chart, in which time is the horizontal axis and human civilization degree is vertical axis. It shows the acceleration characteristic of human civilization development. Social development has been faster since the advent of the twenty-first century, and the characteristics of modern society are becoming more and more diversified. Characteristics of population aging are blended with other social characteristics.

The blending is mainly reflected in the following aspects:

(1) Population aging exists with the rapid development of network and informatization (Czaja \& Lee, 2007).

(2) Population aging exits with global integration development of economy and culture.

(3) Population aging exists with the rapid development of high and new technology.

(4) Population aging exists with increasing city expansion and labor subdivision.

(5) Population aging exists with the social requirements of sustainable development.

There is a huge contradiction between population aging and the social characteristics of network development, informatization, globalization, technical progress and so on (Coyne \& Nielsen, 2002). This needs to be solved through the combination of policy, industry and design. As for designers, these contradictions mean new development opportunities for design. Modern technologies can be fully used to solve problems in population aging. For example, network terminal, mobile digital products, wearable devices, smart home products and so on can be developed according to the actual needs of the elderly.

\subsection{Medium Factors: Differences in Market Demand of Products for the Elderly}

In addition to the common characteristics of social development which have great impact on product design for the elderly, design demands of the elderly are also subject to the influences of region, culture, economy and other factors.

These factors can be divided into the following aspects:

(1) Unbalanced development of regional economy leads to differences in demands of the elderly for products;

(2) Difference in regional culture leads to differences in demand of the elderly for products;

(3) Different development level of informatization between different regions leads to differences in demand of the elderly for products.

(4) Differences in age, gender, income, occupation, cultural level, occupation, health condition and other factors cause differences in demands of the elderly for products.

These differences have different requirements for the design of products for the elderly. Market segmentation needs to be done according to target customer groups before the development of special products for the elderly.

\subsection{Microcosmic Factors: Contradiction between the Elderly's Demands and Reality}

Characteristics of social development and regional environment constitute objective restrictive factors for the 
design of special products for the elderly. Their specific impacts need to be analyzed according to the psychological needs of the elderly.

Many contradictions are found between the elderly's psychological desire and objective reality, which is mainly reflected as follows:

(1) Contradiction between the desire of the elderly for better life quality and life quality decline caused by biological function degradation (Siu, 2011).

(2) Contradiction between the desire of the elderly for social life and their poor ability of using communication tools (Selwyn, 2003).

(3) Contradiction between the desire of the elderly for long life and difficulty in doing exercise.

(4) Contradiction between the desire of the elderly for keeping up with social development and lack of social activities.

Designers can develop various kinds of products for the elderly according to their psychological needs, so as to solve the problems facing the elderly.

\section{Concept and Nature of Special Product Design for the Elderly}

\subsection{Concept of Special Product Design for the Elderly}

Special products for the elderly are also known as aging products (Luo, 2014) or third age products (Hori \& Cusack, 2006). Generally, they include the elderly's daily necessities, entertainment and leisure products, health care products and many other products (Dou \& Zheng, 2013).

The concept of special product design for the elderly can be summarized as follows: design of special products for the elderly refers to targeted design innovation, which is done according to physiological characteristics, explicit or implicit demands of the elderly to improve their life quality and resolve their practical problems.

\subsection{Similarities and Differences between Design of Special Products for the Elderly and Barrier Free Design and Universal Design}

There are some common features and obvious differences between the design of special products for the elderly and barrier free design and universal design. These should be analyzed and compared in order to avoid confusion and further identify uniqueness of design of special products for the elderly.

There are similarities between the design of special products for the elderly and barrier free design \& universal design in terms of design goals and service object they all aim at improving the life quality of vulnerable groups. Barrier free design also focuses on special demands of vulnerable groups and the elderly, but there are also obvious difference in design nature and content: Barrier free design is mostly applicable to design of building, transportation and others with public environmental characteristics, such as wheelchair channel, blind road, tactile map and so on. Special products for the elderly are not limited to public products they involve a more extensive scope of products, such as entertainment products, rehabilitation products, electronic information products and others for the elderly. It can be said that barrier free design focuses on building an environment which features equal participation between different social groups, while design of special products for the elderly focuses on the improvement in lifestyle of the elderly.

There are also some similarities and differences between design of special products for the elderly and universal design. In terms of similarities, universal design focuses on design according to the demands of disabled individuals, and at the same time, the design can reduce the using difficulty of general public. And the service object of the special product design for the elderly also have certain weakness in body function, in this regard, universal design is similar to design of special products for the elderly (Zhao, 2012). There are also obvious differences in other aspects between the two kinds of design.

For example, the design of special products for the elderly has a clear target group, while universal design is aimed at all users. In addition, universal products can be used by all people, no improvement is needed; while special products for the elderly may not be applicable to other groups.

The acceptance degree of target consumers for relevant products can be used as a basis to judge whether the products are successful.

Differences and similarities between special product design for the elderly, universal design and barrier free design are compared in the following table (refer to Table 1). 
Table 1. Comparison of design of special products for the elderly; barrier free design and universal design* .

\begin{tabular}{ccccc}
\hline Type & Service object & Design content \\
Design of special & $\begin{array}{c}\text { Tarious types of products (live } \\
\text { entertainment, rehabilitation, } \\
\text { information etc) products for the } \\
\text { elderly }\end{array}$ \\
Barrier free design & $\begin{array}{c}\text { The disabled, The } \\
\text { elderly }\end{array}$ & $\begin{array}{c}\text { Public design environmental } \\
\text { facilities (Channel, The blind, } \\
\text { Tactile map etc) }\end{array}$ \\
Universal design & $\begin{array}{c}\text { All users } \\
\text { Products and facility design for } \\
\text { different people }\end{array}$
\end{tabular}

*The pictures in the table are from the following websites: http://www.aima-idea.comcasedetails; http://www.shijue.mezoneshow_art; http://www.designmoma; http://image.baidu.com/; http://house.dbw.cn/system/2014/06/09/. http://www.ud.org.tw2012portfolio. The pictures are only used as a description of the different types of products and aren't for any commercial purposes. Special thanks to the owners of pictures.

\subsection{Nature and Feature of Design of Special Products for the Elderly}

Through the analysis and comparison of similarities and differences between design of special products for the elderly, barrier free design and universal design, the nature and characteristics of design of special products for the elderly are summarized as follows:

(1) Clear design service object: to specially provide design assistance to the elderly.

(2) Comprehensive design content: to involve various types of products for the elderly, which are related to living, entertainment, leisure, health care, nursing, health, communication etc.

(3) Clear design goal: to solve practical problems of the elderly and improve their life quality, as well as optimize their lifestyle.

\section{Basic Principles of Design of Special Products for the Elderly}

According to the concept of design of special products for the elderly, and nature, rules and characteristics of design of special products for the elderly, the basic principles of design of special products for the elderly can be summarized from the perspectives of function, form, structure and value as follows:

\subsection{Functional Design: Intuitive, Simple and Easy to Use}

In the functional development of special product design for the elderly, special product development should be carried out according to physiological function decline characteristics and psychological characteristics of the elderly. Alternatively their existing problems should be resolved to reduce their physiological and psychological obstacles when using conventional products by making these meet the demands of the elderly well. In terms of functional design, design of special products for the elderly should be intuitive, simple and easy to use.

(1) Intuitive: product functions and operational methods should be clear and intuitive (Fisk et al., 2004) and not cause any confusion, so that the elderly can use them easily.

(2) Simple: Functions should be simple, and special design needs to be done according to particular demands. The main functions and features need to be designed according to major demands of the elderly and functions 
that are not frequently used by them should be reduced.

(3) Easy to use: Products should be easy to use (Zhou, 2008), with great convenience, availability and operability being emphasized (Hall, 1999). Products should fully meet the physiological and psychological needs of the elderly, with reduced requirements on physical ability of users, such as reducing physical load and enhancing perception ability etc.

\subsection{Exterior Design: Simplicity, Artistry and Maturity}

In addition to meeting functional requirements, products also need to further meet the psychological needs and aesthetic needs of the elderly (Dou \& Zheng, 2013). Products for the elderly generally need simple shape and beautiful appearance. Reduced contrast between colour and texture design, maturity and a sense of intimacy meet the elderly's aesthetic psychology.

\subsection{Ergonomics Design: Safety, Comfort and Applicability}

Products need to comply with the ergonomics standards of the seniors (Charness, 2008; Fisk et al., 2004). Potential safety problems of products need to be eliminated and sharp angles and protrusions avoided. They should also offer comfort and great applicability. For example, products must be suitable for the characteristics of the elderly and have an anti-fall protection function. Water, electricity, gas and other equipment need to ensure safe use. For example, the elderly often forget to turn off the gas valve after cooking, which can lead to a huge security risk. Safety, sound and lighting reminders should be adopted in design.

\subsection{Structure Design: Feasibility, Firmness and Durability}

Scientific and reasonable structure design can be carried out according to the use frequency and related standards of the product. Products need to not only ensure the required strength of the product structure and materials, but also meet the needs of production and economy and have the feasibility of manufacturing. The product must be of good quality, reliable, durable, and needs to ensure normal operation in the product life cycle.

\subsection{Value Design: Economical Feature, Sustainability and Cultural Connotation}

Economical features, controllable costs and meeting market demands can bring certain economic value to relevant enterprises. Environmentally friendly materials and modular design methods should be adopted to enhance sustainable features and social attributes of products. In addition, products need to reflect certain geographical and cultural connotations, and be consistent with local social development and market situations, as well as meeting the cultural and psychological needs of the elderly (Huppert, 2003).

\section{Theoretical Model of Special Product Design for the Elderly}

A theoretical model of special product design for the elderly can be built according to background factors, nature and characteristics, as well as the basic principles of special product design for the elderly (shown as Figure 1).

The model includes the "influencing factors analysis__ design theory induction_—inspection \& evaluation" mode, which shows inducing process and key content of theory of special product design for the elderly. The upper part of the model is described in detail in the previous part of the paper. Concept, characteristics and design principles of special product design for the elderly are derived through background analysis. Among them, summary and analysis of design principles form the core content of the model. This is reflected in the intuitive, simple and easy-to-use features of products in function design; Simplicity, artistry and maturity are reflected in exterior design; Unity of safety, comfort and applicability are reflected in ergonomics design; Feasibility, firmness and durability are reflected in structure design; while economical features, sustainability and cultural connotation are reflected in value design. In addition to theoretical induction, design demand analysis, virtual simulation, ergonomics data, process test, value analysis are used for building the design platform. Then the design theory is verified and improved through design evaluation and user experience. A model for the design theory of special products for the elderly is built through the above process. 


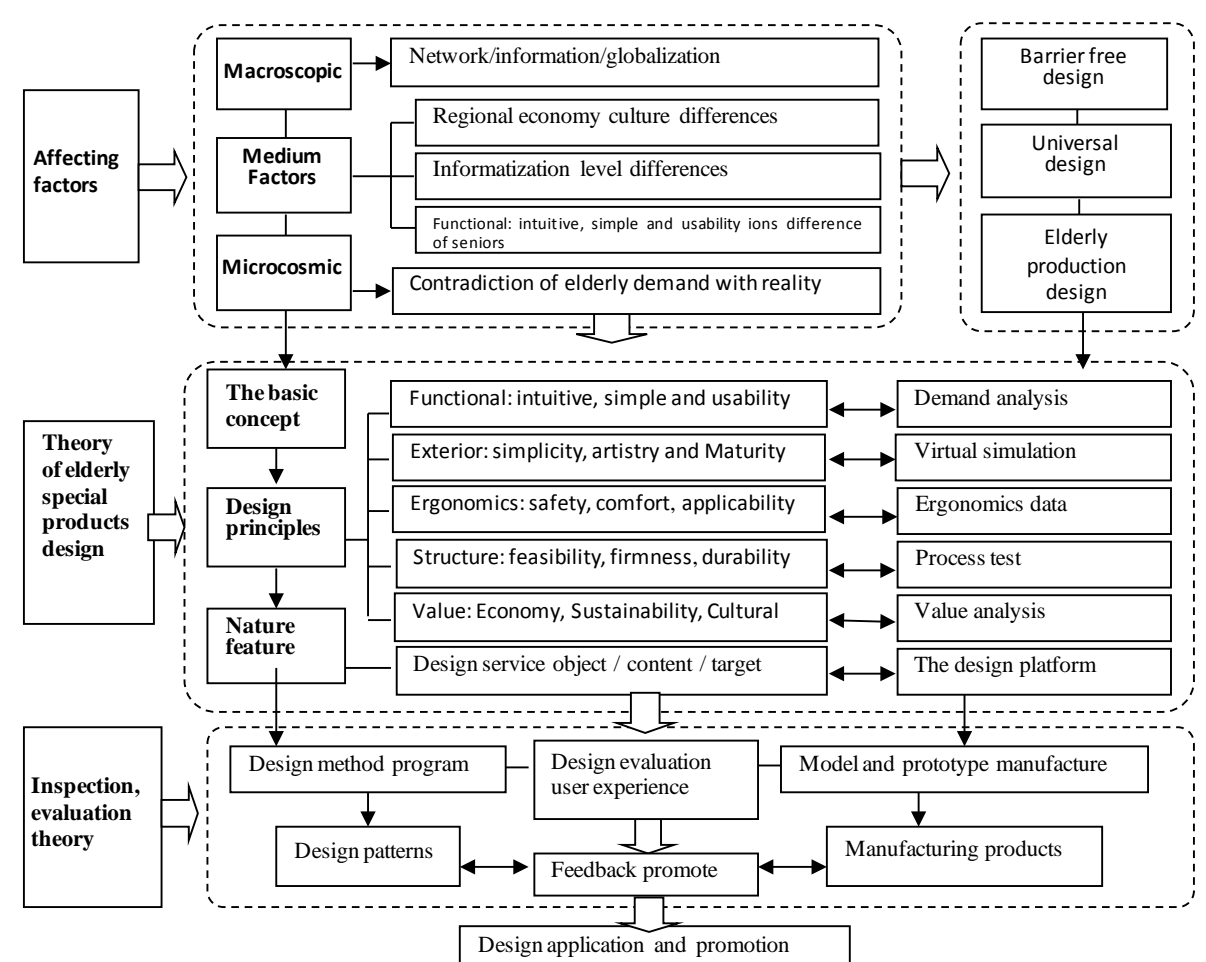

Figure 1. Theoretical model of special product design for the elderly.

\section{Conclusion}

This paper introduces the restrictive conditions of special product design for the elderly through the analysis of relevant factors. Further, the concept, nature and characteristics of special product design for the elderly are summarized and basic design principles are also presented. Finally, through the combination of relevant factors, a model for special product design for the elderly is built; the model shows derivation process and key content of special product design for the elderly and lays a foundation for the development of a theory of special product design for the elderly.

\section{Fund Project}

The research was funded by China Scholarship Fund (project number: 201406955046); The Fundamental Research Fund for the Central Universities (project number: 141316002); Teaching research fund of Hubei province (project number: 2012123).

\section{References}

Bertera, E. M., Bertera, R. L., Morgan, R., Wuertz, E., \& Attey, A. M. O. (2007). Training Older Adults to Access Health Information. Educational Gerontology, 33, 483-500. http://dx.doi.org/10.1080/03601270701328250

Charness, N. (2008). Aging and Human Performance. Human Factors: The Journal of the Human Factors and Ergonomics Society, 50, 548-555. http://dx.doi.org/10.1518/001872008X312161

Coyne, K., \& Nielsen, J. (2002). Web Usability for Senior Citizens: 46 Design Guidelines Based on Usability Studies with People Age 65 and Older. Nielsen Norman Group Report, Fremont, CA: Nielsen Norman Group.

Czaja, S. J., \& Lee, C. (2007) The Impact of Aging on Access to Technology. Universal Access in the Information Society, 5 , 341-349. http://dx.doi.org/10.1007/s10209-006-0060-X

Dou, J. H., \& Zheng, Y. L. (2013). Research on Designing Pleasant Products for the Empty Nest Elderly. Packaging Engineering, 34, 34-37.

Fisk, A. D., Rogers, W. A., Charness, N., Czaja, S. J., \& Sharit, J. (2004). Designing for Older Adults: Principles and Creative Human Factors Approaches. Boca Raton, FL: CRC Press. http://dx.doi.org/10.1201/9781420023862 
Huppert, F. (2003). Designing for Older Users. In J. Clarkson, R. Coleman, S. Keates, \& C. Lebbon (Eds.), Inclusive Design: designing for the whole population. London: Springer-Verlag. http://dx.doi.org/10.1007/978-1-4471-0001-0_2

Hall, R. R. (1999). Usability and Product Design: A Case Study. In W. Greeen, \& P. Jordan (Eds.), Human Factors in Product Design Current Practice and Future Trends (pp. 85-91). Philadelphia, PA: Taylor and Francis.

Hori, S., \& Cusack, S. (2006). Third-Age Education in Canada and Japan: Attitudes toward Aging and Participation in Learning. Educational Gerontology, 32, 463-481.

Luo, J. Y. (2014). Home Welfare Products Design for Older Users. Packaging Engineering, 35, 42-45.

Siu, K. W. M., Ng, A. W. Y., \& Chan, C. C. H. (2011). The Imagery Vividness and Preferences of Older People: Implications for Visualization in Concept Design. The Design Journal, 14, 413-426. http://dx.doi.org/10.2752/175630611X13091688930417

Zhao, C. (2012). Design for Ageing: An Inclusive Stance an Critical Attitude. Zhuangshi, 9, 16-21.

Zhou, J. (2008). Study of Design and Development Principles of Product for the Elderly. Packaging Engineering, 29, 145147. 